\title{
Disorders of Sexual Differentiation: A study on the Incidence and Types of Female Pseudo Hermaphrodites
}

\section{J.Radhika *1, C.Bhuvaneswari ${ }^{2}$, Arudyuti Chowdhury ${ }^{3}$.}

${ }^{* 1}$ Associate Professor, Department of Anatomy, SRM M edical College Hospital \& Research Centre, SRM University, Kattankulathur, India.

${ }^{2}$ Assistant Professor, Department of Anatomy, SRM M edical College Hospital \& Research Centre, SRM University, Kattankulathur, India.

3 Professor, Prasad Institute of Medical Sciences, Lucknow, India.

\section{ABSTRACT}

Aim: The present study was done to find out the prevalence of disorders of sexual development in our population and the genetic and environmental factors in the causation of disorders. Primarily, the study focused on the incidence and types of Female Pseudo Hermaphrodites.

Materials and Methods: The present study included 300 cases over a period of 3 years in the Institute of Obstetrics and Gynaecology, Egmore. Of these 300 cases, 29.3\% were identified as Female pseudo hermaphrodite by examining the external and internal genitalia and through Karyotypes, ultrasound and hormonal assay.

Results and Conclusion: The increased incidence of Female Pseudo hermaphrodite was found to be due to avoidable factors except for a few cases. This highlights the importance of early diagnosis for assigning appropriate gender without causing much social and emotional problems.

KEY WORDS: Ambiguous Genitalia, Female Pseudo Hermaphrodite, Masculinization Of External Genitalia, Karyotype.

Address for correspondence: Dr.J.Radhika, M.D, Ph.D, Associate Professor, Department of Anatomy, SRM Medical College Hospital \& Research Centre, SRM University, Kattankulathur, India. E-Mail: jradhikakrishnan@gmail.com

\begin{tabular}{|c|c|c|}
\hline \multicolumn{3}{|c|}{ Online Access and Article Informtaion } \\
\hline 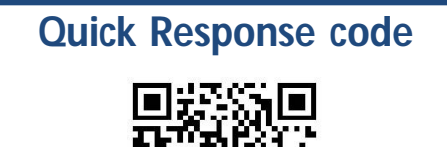 & \multicolumn{2}{|c|}{$\begin{array}{l}\text { International Journal of Integrative Medical Sciences } \\
\text { ww www.imedsciences.com }\end{array}$} \\
\hline 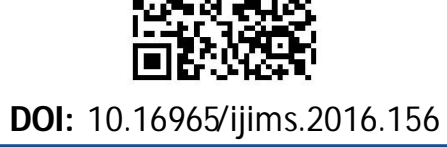 & $\begin{array}{l}\text { Received: 28-11-2016 } \\
\text { Reviewed: 28-11-2016 }\end{array}$ & $\begin{array}{l}\text { Accepted: 20-12-2016 } \\
\text { Published: 31-12-2016 }\end{array}$ \\
\hline Source of Funding: Self & \multicolumn{2}{|c|}{ Conflicts of interest: None } \\
\hline
\end{tabular}

\section{BACKGROUND}

Ambiguous Genitalia refers to any infant with a confusing appearance of the external genitalia. In a human being any discrepancy between the internal gonad and external genitalia is referred to as intersex state.

Prenatally sexual differentiation follows a specific sequence of events. First is the establishment of genetic sex. Second under the control of the genetic sex the gonads differentiate determining the hormonal environment of the embryo, the differentiation of the internal duct system and the formation of external genitalia [1].

M aleness or femaleness may be assessed by at least five points, namely chromosomal constitution or karyotype, gonadal type, phenotype or bodily configuration, chemical or hormonal and psychological make up. But when there is a continuity in which there is mixed characters of male and female, pseudo hermaphroditism is exhibited.

Female Pseudo Hermaphrodite: Female Pseudo Hermaphroditism are 46XX genetic females who have been exposed to excessive amounts of 
androgen at some period of time before 12 weeks of pregnancy or during the first trimester. They have normal internal genitalia with ovaries, fallopian tubes and a uterus but the external genitalia are masculinized to a degree that may vary from minimal phallic enlargement to complete masculinization in which the labio scrotal folds are fused. The differential point is that they do not have palpable gonads [2]. Sex assignment should be females regardless of any contrary impression given by external genitalia. Persisting androgenic stimulation can be suppressed and genital ambiguity corrected surgically.

The androgens responsible for genetic ambiguity is due to endogenous causes due to biochemical block impeding the formation of cortisol (Androgenital syndrome) or due to exogenous causes - due to androgens which are elaborated by maternal tumor and ingestion of hormones for maintenance of pregnancy during the $1^{\text {st }}$ trimester.

Adrenogenital Syndrome [3] results due to several enzymatic deficiencies which have in common the effect of impeding the formation of cortisol.

\section{The 3 enzyme defects being}

\section{- 301 dehydrogenase deficiency}

- 21 hydroxylase deficiency

- 11 hydroxylase deficiency

01 dehydrogenase deficiency: It [4] is the rarest of the three and since it is the one associated with the greatest degree of salt wasting, long time survivors are few. Masculinization is not as severe as that seen in other forms of Ambiguous Genitalia.

21 hydroxylase deficiency: The block resulting from deficiency of this enzyme leads to elevated levels of serum 17 hydroxy progesterone and increased excretion of its metabolite pregnanetriol. Hence salt wasting is common and generally requires treatment. The result is large muscular child but short adult. M enses and breast development are suppressed by elevated serum androgen [5].

Prenatal Diagnosis of adrenal hyperplasia due to 21 hydroxylase deficiency by allele specific hybridization and Southern blot [6].

$\mathbf{1 1}$ hydroxylase deficiency: It results in salt retention and androgenetic features are similar to 21 hydroxylase deficiency. However, because of salt retention they are prone to develop Hypertension [7].

Steroid 11 beta-hydroxylase ( $\mathrm{P}-450$ (11) beta) is a mitochondrial cytochrome. P-450 enzyme is necessary for cortisol biosynthesis. Deficiency of this causes Congenital Adrenal Hyperplasia [8].

Exogenous Androgens: Androgen precursors given to pregnant mothers [9] readily cross the placental barrier. When this occurs at the first trimester, masculinization of the fetus occurs. Progestational agents given to mother to prevent miscarriage also cause masculinization of the fetus.

The degree of masculinization produced depends upon the dose and timing of medication [10]. The derangement is milder than seen in Androgenital syndrome.

Androgen secreting tumors (Arrhenoblastoma or Luteoma) in mothers [11] can cause masculinized females having empty scrotum and masculinized external genitalia [12].

\section{MATERIALS AND METHODS}

All babies delivered at the Institute of Obstetrics and Gynaecology, Egmore, M adras- 8 during the period of study from June 1991- 31 ${ }^{\text {st }}$ M ay 1994 were screened for Ambiguous Genitalia and for associated anomalies. Also, patients referred to the Genetic Clinics were examined. All live births and still births with Ambiguous Genitalia were studied prospectively according to a defined protocol comprising of clinical and laboratory investigations. Only cases presented with ambiguity of the genitalia have been included in this study (Ovarian dysgenesis, Turner's syndrome and seminiferous tubules dysgenesis (KFS) have been excluded from this study as they form a separate entity and are beyond the scope of this study).

History Recording of the patient (Child): The points noted are: Age at presentation, Age at onset of symptoms, Preterm or term, Still birth/ Live birth, Presence of symptoms like diarrhea, vomiting/dehydration.

Clinical Examination: A detailed head to foot examination made which included weight, height and any dysmorphic features indicative 
of a syndrome.

Examination of genitalia: Phallus - Present/ Size Or Clitoris - Absent/Size, Scrotal sac Present /Absent/ Size/rugae, bifid, Labia Normal, hypoplastic or abnormal, Urethral opening - Site, Vaginal opening - Present/ absent, Anal opening, Gonad site/size, Inguinal Hernia or any other abnormality.

\section{Parental History}

Residence: Nearby Factories and Industrial areas from which toxic effluents and pollutants are present.

Occupation: Father or mother exposing them to radiation and toxic chemicals. Example, Farmers exposed to pesticides, laboratory exposure to chemicals or radiation.

Habits: Alcoholism, smoking, tobacco chewing, Paternal age, History of Illness, and or intake of drugs by father prior to conception

Maternal Age: Periods-regular/irregular, history of intake of hormones, Hormone Preparation for (1) Postponement of periods (2) contraception (3) To induce abortion. History of intake of drugs like steroids or other drugs periconceptionally.

Maternal illness: diabetes, pyrexia due to any causes - Tumors in the mother.

Pedigree charting: History of consanguinity, Fetal loss in the family, Infertility, M alformation, Neonatal deaths, Ambiguous Genitalia, Excess female births (Testicular Feminization Syndrome), Recurrence in the sibling.

\section{Investigations for the patient:}

Biochemical Examinations: Serum Electrolytes

Radiological a) Ultrasonogram of pelvis to see for uterus/ ovaries/ testis, gonads and associated anomalies b) Genitogram -to see for Wolfian and Mullerian remnants. Diagnostic laparoscopy to look for the uterus and locating gonad or biopsy if necessary, Endocrine Investigations were done for some cases. Clinical photography for documentation and follow - up.

Autopsy in still birth to see for malformation, Karyotyping was done by standard method.

\section{RESULTS}

Female Pseudo Hermaphrodites were identified using the above Materials and Methods by examination of the external Genital appearance Int J Intg M ed Sci 2016;3(12):455-60. ISSN 2394 - 4137 and correlating it with karyotyping, ultrasound and hormonal assay.

\section{Clinical Types of Cases Encountered:}

Table 1: Spectrum of Female Pseudo Hermaphrodite.

\begin{tabular}{|l|c|}
\hline \multicolumn{1}{|c|}{ Case Type } & Number \\
\hline $\begin{array}{l}\text { Female Pseudo Hermaphrodite } \\
\text { Total }\end{array}$ & 88 \\
\hline $\begin{array}{l}\text { Female Genitalia with Clitoral } \\
\text { Hypertrophy and no gonads felt } \\
\text { without pigmentation }\end{array}$ & 40 \\
\hline $\begin{array}{l}\text { Female Genitalia with Clitoral } \\
\text { Hypertrophy and Precocious } \\
\text { Puberty and no gonads felt }\end{array}$ & \\
\hline Large phallus and fused Labia & 2 \\
\hline $\begin{array}{l}\text { Large phallus with hypospadias } \\
\text { and absent gonads }\end{array}$ & 16 \\
\hline Cloacal anomaly & 23 \\
\hline Trisomy 13 & 1 \\
\hline Trisomy 18 & 1 \\
\hline Triploidy & (Still birth) \\
\hline
\end{tabular}

Table 2: Female Pseudo Hermaphrodites (Genetic Types).

\begin{tabular}{|l|c|c|}
\hline \multicolumn{1}{|c|}{ Case Type } & Number & Percentage \\
\hline Chromosomal & 7 & $7.95 \%$ \\
\hline $\begin{array}{l}\text { Single Gene Congenital } \\
\text { Adrenal Hyperplasia }\end{array}$ & 41 & $46.59 \%$ \\
\hline $\begin{array}{l}\text { Maternal Ingestion of } \\
\text { Hormones }\end{array}$ & 40 & $45.45 \%$ \\
\hline $\begin{array}{l}\text { Probable exposure to } \\
\text { teratogen like Alcoholism } \\
\text { toxic chemicals }\end{array}$ & NIL \\
\hline
\end{tabular}

This study shows that $\mathbf{5 0 \%}$ of the cases are due to maternal ingestion of hormones which could be avoided.

The images for the above findings are present in the lllustrations section at the end of the document (Figure 1 to Figure 7). Consent had been obtained from the parents for the study.

Fig. 1: Classification of Ambiguous Genitalia. 
Fig. 2: Classification of Female Pseudo Hermaphrodites.

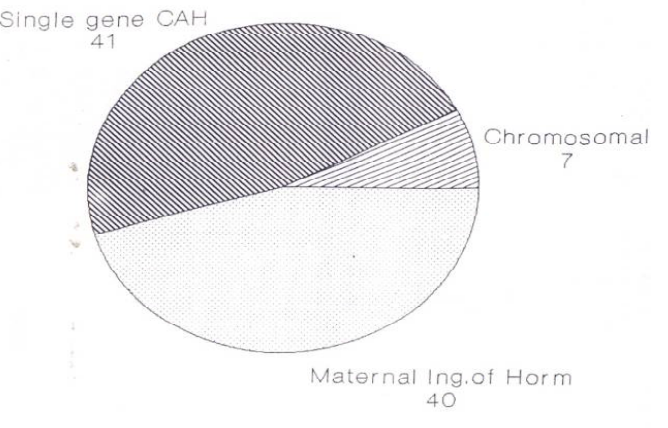

$50 \%$ of the cases are due to maternal ingestion of hormones

Fig. 3: Paternal Factors in Female Pseudo Hermaphrodite.

\begin{tabular}{|c|c|c|c|c|}
\hline \multicolumn{5}{|c|}{$\begin{array}{l}\text { PATERNAL FACTORS FOR } \\
\text { FEMALE PSEUDO HERMAPHRODITE ( } 88 \text { CASES) }\end{array}$} \\
\hline \multicolumn{2}{|c|}{ AGE } & \multicolumn{3}{|c|}{ Habits } \\
\hline Group & No. & Smoking & Alcoholism & $\begin{array}{l}\text { Expos to } \\
\text { Radiation }\end{array}$ \\
\hline Below 20 years & 4 & & & \\
\hline $20-30$ yrs & 38 & 25 & 30 & NII \\
\hline $30-40$ yrs & 38 & & & \\
\hline $40 \&$ above & 8. & & & \\
\hline
\end{tabular}

Fig. 4: M aternal Factors for Female Pseudo Hermaphrodite.

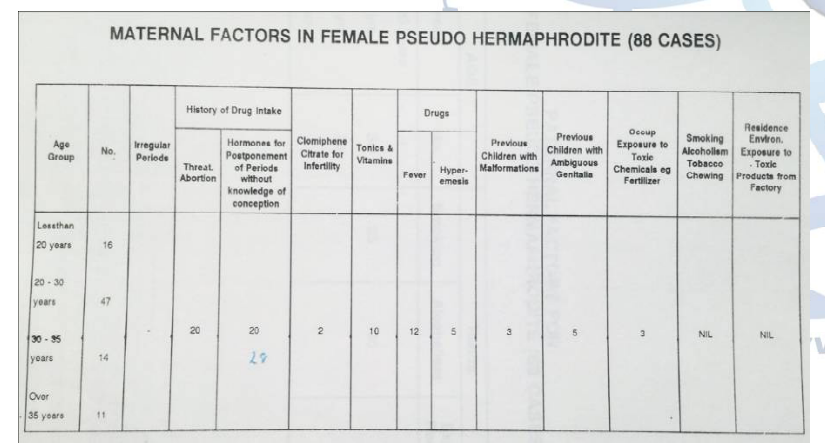

Fig. 5: G Banded M etaphase with Karyotype 46XX.

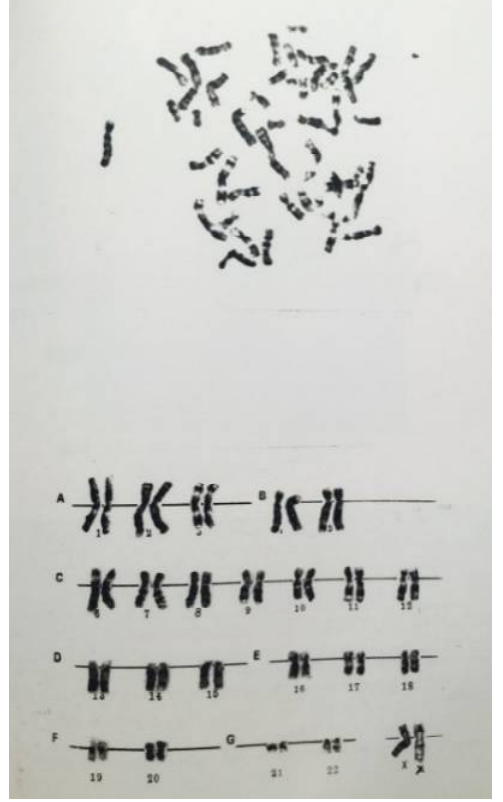

Int J Intg M ed Sci 2016;3(12):455-60. ISSN 2394 - 4137
Fig. 6: Clitoral Hypertrophy with fused Labia and no other phenotypic abnormality.

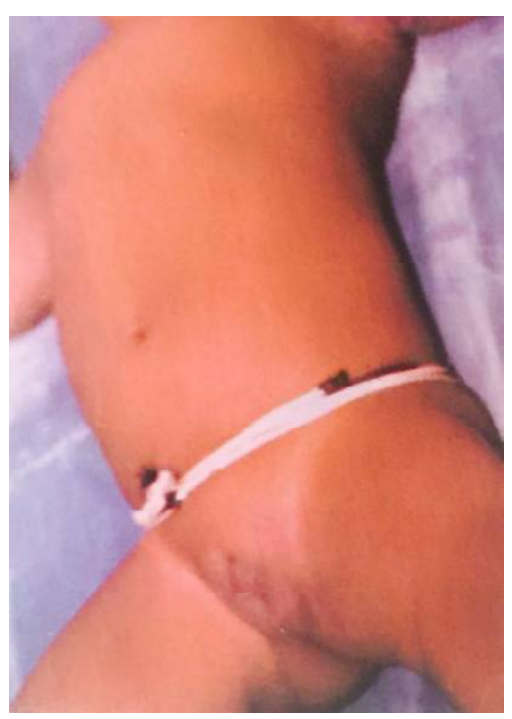

Fig. 7: Clitoral Hypertrophy with fused labia, darkly pigmented skin with urethral orifice present.

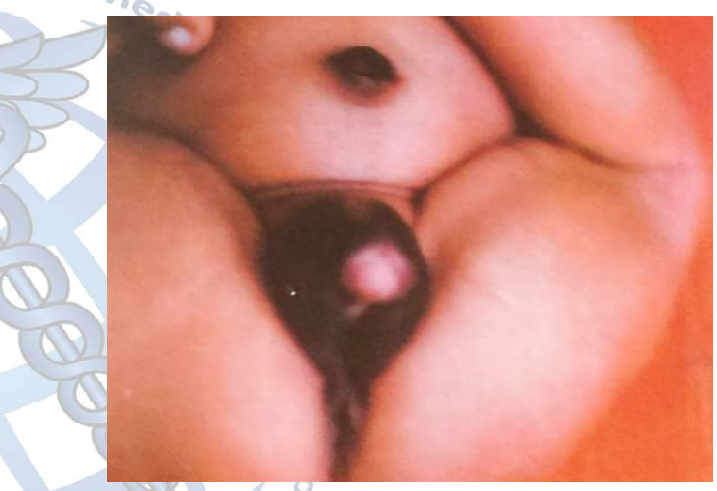

\section{DISCUSSION}

Incidence regarding prevalence of intersex (type) in world population, predictions is not clearly available.

In a study in S. America [13] shows that 1/20,000 birth had Ambiguous Genitalia out of which at least $1 / 4$ were due to Congenital Adrenal Hyperplasia. In Lyons pediatric clinic, 315 infants/children have been examined for intersexuality. Female pseudo hermaphroditism constitutes $43 \%$ of cases with great majority due to 21 hydroxylase deficiency.

Z.M Patel's [14] study of 79 cases with Ambiguous Genitalia showed equal number of male and female pseudo hermaphrodites.

In our study of about 300 cases of Ambiguous Genitalia for 4 years we have found 88 cases where Female Pseudo Hermaphrodite constituted $28.3 \%$. Such an extensive study has not been conducted so far.

Types: In a study by Castilla EE [13] in SAmerica, 
of 20,000 live births half of them were due to Congenital Adrenal Hyperplasia.

ZM Patel's [14] study of 79 causes showed that among Female Pseudo Hermaphrodites more than $50 \%$ were due to Congenital Adrenal Hyperplasia.

In our study, $43 \%$ of Female Pseudo Hermaphrodites were due to Congenital Adrenal Hyperplasia.

Age Group: Maternal age group was between 20-30 years. Lower maternal age causes low birth weight. Paternal age group - about 42\% belonged to the age group of 20-40 years of age.

Consanguinity: The frequency of consanguinity in our population is $25 \%$. In our study $50 \%$ of marriages are consanguineous. This high frequency can be attributed to the Autosomal Recessive inheritance of Congenital Adrenal Hyperplasia. This is an avoidable cause

$M$ aternal ingestion of drugs can cause ambiguity of external genitalia. In our study $50 \%$ of cases gave History of progesterone intake during the first 2 months of pregnancy.

\section{CONCLUSION}

Intersex can occur from a variety of causes. Hence by following a systemic approach to the diagnosis and management one can always assign a definitive sex to their patients. The emphasis should be on early diagnosis for proper management. It may even be lifesaving in conditions like Congenital Adrenal Hyperplasia.

This study highlights the importance of proper Pre-Conceptional \& prenatal measures to avoid the occurrence of Ambiguous Genitalia in fetus.

Prenatal diagnosis is possible by

- Ultra sound to see for fetal abnormalities

- Fetal sexing by Karyotyping from amniotic fluid

- Hormonal assay can be done for cases with Congenital Adrenal Hyperplasia

- Recent studies have shown diagnosis by M olecular Study of Genes involved in synthesis of enzymes responsible for preventing Congenital Adrenal Hyperplasia.

M ost of the Female Pseudo Hermaphrodites in this study which constituted about $29.3 \%$ were found to be due to avoidable factors. Some of the female pseudo hermaphrodites have been reared as males even beyond childhood. This highlights the importance of early diagnosis if appropriate gender must be assigned without causing many emotional and social problems.

The next important step will be early recognition by the medical officer even in the smallest peripheral centers from where they can refer to appropriate centers for proper diagnosis and management.

\section{REFERENCES}

[1]. M ONEY.J. DERORE: H NORM AN B.F Gender Identity \& Gender Transposition Longitudinal outcome study of 32 male hermaphrodites assignes as girls J. sex Martial Ther 1986; 12: 165

[2]. RAPPORT R: Nichoul Fekete C: Pseudo hermaphroditism feminine, Etiologie et physiopa thologie. Annd' Endocrin 1980; 41:345

[3]. Bongiovanni AM : Congenital Adrenal Hyperplasia and related conditions. In StanburyJ, Wyngaarden J, Fredrickson D (eds): The Metabolic Basis of Inherited Disease, New York, M cGraw-Hill, 1978; $p$ 868

[4]. Bongiovanni AM: Congenital Adrenal Hyperplasia due to 3â-hydroxysteroid dehydrogenase. In New MI, Levine LS (eds): Adrenal Diseases in Childhood, Basel, Karger, 1984; pp 72-82.

[5]. MAXTED W, BAKER R, M c Crystal It, et al. complete masculinization of the external genitalia in congenital adrenocortical hyperplasia. Presentation of two cases. J Urol 1965; 94:266.

[6]. SPEISER P.W, White PC, Dupont et al: Prenatal diagnosis of congenital adrenal hyperplasia due to 21-hydroxylase deficiency by allele-specific hybridization and Southern blot. Human Genetics 1994; 93(4):424-8.

[7]. CHANG SH, Lee HH et al: Congenital adrenal hyperplasia with 11 beta-hydroxylase deficiency. Journal of the Formosan M edical Association 2004; 103(11):860-4.

[8]. MORNET E, Dupont J, Vitek A, White PC. Characterization of two genes encoding human steroid 11 beta-hydroxylase (P-450(11) beta). J Biol Chem. 1989; 264(35):20961-20967.

[9]. Grumbach M, Ducharme J: The effects of androgens on fetal sexual development: Androgen-induced female pseudohermaphroditism. Fertil Steril 1960; 11: 157.

[10]. WILKING L: Masculinization of female fetus due to use of orally given progestin 1960; JAM A 172:1028.

[11].BRENTANALL CP: A case of arrhenoblastoma complicating pregnancy J.Obstet Gynecol Brit Emp 1945; 52:235.

[12]. ROBERTA A. PAGON M.D: Diagnostic Approach to the New born with Ambiguous Genitalia. Pediatric Clinics of North America. 1987; Vol.34, No.4. 
[13].CASTILLA EE: Orioli IM, Lugarinho R, Dutra G. Epidemiology of Ambiguous Genitalia in South America, Am J. Med Genet. 1987; 27: 337-343.
[14]. PATEL Z.M : LM Ambani, S.J. Dalal V.V. Gokaru, MP Desai, C.S. Rao. RH Suchak, UM Joshi 1983;20.

How to cite this article:

J.Radhika, C.Bhuvaneswari, Arudyuti Chowdhury. DISORDERS OF SEXUAL DIFFERENTIATION: A STUDY ON THE INCIDENCE AND TYPES OF FEM ALE PSEUDO HERM APHRODITES. Int J Intg Med Sci 2016;3(12):455-460. DOI: 10.16965/ijims.2016.156 